\title{
Vacancy Formation in Fe-Al of B2 and $\mathrm{DO}_{3}$ Alloys
}

\author{
J. KAnsY ${ }^{a *}$, A. HANC ${ }^{a}$, D. GIEBEL ${ }^{a}$ AND M. JABŁOŃSKA ${ }^{b}$ \\ ${ }^{a}$ Institute of Materials Science, University of Silesia \\ Bankowa 12, 40-007 Katowice, Poland \\ ${ }^{b}$ Institute of Materials Science, Silesian Technical University \\ Krasińskiego 8, 40-019 Katowice, Poland
}

The positron lifetime spectroscopy is employed to study vacancy formation in intermetallic phases of $\mathrm{DO}_{3}$ and $\mathrm{B} 2$ structures from $\mathrm{Fe}-\mathrm{Al}$ system as a function of $\mathrm{Al}$ concentration, ternary additive $(\mathrm{Cr})$ and their thermal treatment. Lifetime spectra were fitted en block by a simple trapping model encoded directly to the software (computer program LT-9). In the investigated range of $\mathrm{Al}$ concentration $(28,38,42$, and 45 at\%) only two types of defects are found. In $\mathrm{DO}_{3}$ region a single type of defects (characterized by positron lifetime $\tau_{1}=170 \pm 2 \mathrm{ps}$ ) is detected and indicated as vacancies in the Fe sublattice $\left(\mathrm{V}_{\mathrm{Fe}}\right)$. In $\mathrm{B} 2$ region a small amount of an additional type of defects (characterized by positron lifetime $\tau_{2}=214 \pm 13 \mathrm{ps}$ ) appears. Supposedly, these are vacancies in $\mathrm{Al}$ sublattice $\left(\mathrm{V}_{\mathrm{Al}}\right)$. For Fe28Al and $\mathrm{Fe} 28 \mathrm{Al}$ Cr samples changes in $\mathrm{V}_{\mathrm{Fe}}$ concentration are determined as a function of the sample composition, annealing time at $1000^{\circ} \mathrm{C}$ and quenching the samples to air and oil. The defect concentration increases with increase in $\mathrm{Al}$ content. For FeAl with $\mathrm{Al}$ above 38 at\%, the total concentration of defects is so high that positrons are exclusively trapped by defects. Therefore the concentrations $\mathrm{V}_{\mathrm{Al}}$ and $\mathrm{V}_{\mathrm{Fe}}$ cannot be determined separately. However, the ratio of $\mathrm{V}_{\mathrm{Al}}$ concentration to $\mathrm{V}_{\mathrm{Fe}}$ concentration is estimated as a function of $\mathrm{Al}$ content.

PACS numbers: 78.70.Bj, 71.55.Ak

\section{Introduction}

Iron aluminides are known as useful materials owing to high-temperature corrosion resistance, mechanical strength, and relatively low density [1]. The mechanical properties of high-temperature intermetallic alloys are related to point defects and their concentration. It is well known that upon rapid quenching from

*corresponding author; e-mail: kansy@us.edu.pl 
elevated temperatures, iron aluminides retain a high concentration of thermal vacancies, which frozen, increase their yield strength and hardness at room temperature [2]. However, the technical application of these alloys is restricted presently by poor ductility at low temperatures and low fracture toughness [3-8]. Properties like creep, sintering, oxidation, and diffusion are influenced or even determined by thermal defects like vacancies. For this reason, an exact systematic analysis of the defect formation and their characterization are decisively important for understanding of these systems. It is expected that the concentration of vacancies can be strongly changed in the aluminides with the variation of heat and mechanical treatment, together with the composition modification of the aluminides by transition metal ternary additives [5-14]. Because of its extreme sensitivity, the positron annihilation technique represents an excellent method for the study of atomic defects.

In this work, we employed the positron lifetime spectroscopy in a study of vacancies formation in intermetallic phases of the $\mathrm{DO}_{3}$ and $\mathrm{B} 2$ structures from the $\mathrm{Fe}-\mathrm{Al}$ system as a function of $\mathrm{Al}$ concentration, ternary additive $(\mathrm{Cr})$, and their thermal treatment.

\section{Experimental}

The samples were prepared by melting in spinel $\mathrm{Al}_{2} \mathrm{O}_{3} \times \mathrm{MgO}$ crucibles in an induction furnace at vacuum of $10^{-2}$ Torr. They were obtained from ARMCO

TABLE I

The chemical composition (at\%) and the thermal treatment of investigated samples. The additives (Mo-0.2, C-0.1, Zr-0.05, B-0.01 at\%) were added in order to improve thermal and mechanical properties of alloys.

\begin{tabular}{|c|c|c|c|c|c|}
\hline \multirow{2}{*}{$\begin{array}{l}\text { Symbol of } \\
\text { sample }\end{array}$} & \multicolumn{3}{|c|}{ Composition [at\%] } & \multirow[t]{2}{*}{ Structure } & \multirow[t]{2}{*}{ Heat treatment } \\
\hline & $\mathrm{Al}$ & $\mathrm{Cr}$ & $\mathrm{Fe}$ & & \\
\hline $28 \mathrm{~A}$ & 28.0 & - & 71.64 & $\mathrm{DO}_{3}$ & \multirow{5}{*}{$\begin{array}{l}\text { annealed for } 48 \mathrm{~h} \text { at } 1000^{\circ} \mathrm{C} \text {, } \\
\text { slowly cooling }\end{array}$} \\
\hline $38 \mathrm{~A}$ & 38.0 & - & 61.64 & $\mathrm{~B} 2$ & \\
\hline $42 \mathrm{~A}$ & 42.0 & - & 57.64 & $\mathrm{~B} 2$ & \\
\hline $45 \mathrm{~A}$ & 45.0 & - & 54.64 & B2 & \\
\hline Cr A & \multirow{5}{*}{28.0} & \multirow{5}{*}{5.0} & \multirow{5}{*}{66.64} & \multirow{5}{*}{$\mathrm{DO}_{3}$} & \\
\hline Cr A48 -Qoil & & & & & $\begin{array}{c}\text { Annealed for } 48 \mathrm{~h} \text { at } 1000^{\circ} \mathrm{C} \text {, } \\
\text { quenched to oil }\end{array}$ \\
\hline Cr A48 -Qair & & & & & $\begin{array}{c}\text { annealed for } 48 \mathrm{~h} \text { at } 1000^{\circ} \mathrm{C} \text {, } \\
\text { quenched to air }\end{array}$ \\
\hline Cr A24 -Qoil & & & & & $\begin{array}{l}\text { annealed for } 24 \mathrm{~h} \text { at } 1000^{\circ} \mathrm{C} \text {, } \\
\text { quenched to oil }\end{array}$ \\
\hline Cr A24 -Qair & & & & & $\begin{array}{c}\text { annealed for } 24 \mathrm{~h} \text { at } 1000^{\circ} \mathrm{C} \text {, } \\
\text { quenched to air }\end{array}$ \\
\hline
\end{tabular}


iron, aluminum and chromium of $99.98 \%$ purity, and from small amount of other additives (Table I). The additives (Mo-0.2, C-0.1, Zr-0.05, B-0.01 at \%) were added in order to improve thermal and mechanical properties of alloys. The ingots were re-melted three times to insure homogeneity and annealed in a vacuum furnace (CARBOLITE) for $48 \mathrm{~h}$, and then cooled down slowly with the furnace. The X-ray diffraction analysis indicated the disordered $\mathrm{DO}_{3}$ phase $(\mathrm{Fe} 28 \mathrm{Al}$ and $\mathrm{Fe} 28 \mathrm{Al} 5 \mathrm{Cr})$ or ordered $\mathrm{B} 2$ phase $(38-45$ at\% $\mathrm{Al})$. The samples from the $\mathrm{DO}_{3}$ region which contained $5 \%$ at Cr were additionally annealed for 24 or $48 \mathrm{~h}$ at $1000^{\circ} \mathrm{C}$ in vacuum and then quenched to air or oil. Positron lifetime measurements were made at room temperature with the conventional fast-fast spectrometer with the time resolution of $270 \mathrm{ps}$ for Co-60. The positron source of activity about 740 $\mathrm{kBq}$, covered by $5 \mu \mathrm{m} \mathrm{Ni}$ foil, was placed between two pieces of the investigated sample.

A series of 20 lifetime spectra was recorded for each sample. Then the particular spectra of series were added by means of the special procedure accounting the drift of the zero of the time scale [14]. In this way, spectra of very high statistics (about $70 \times 10^{6}$ counts) were obtained.

\section{Numerical analysis}

The experimental data were analyzed with the LT-9 program [15] which, on the contrary to the other existing programs, enables fitting not only a single spectrum but also a series of spectra. The simultaneous fitting leads to a reduction of number of the free fitting parameters because some of the parameters can have

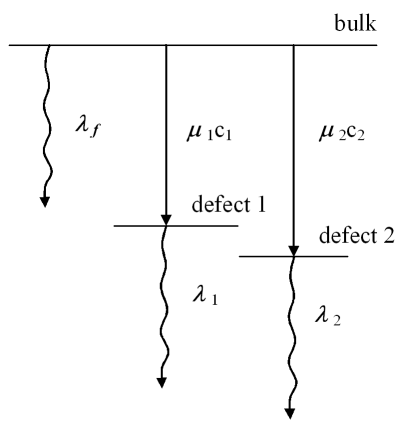

Fig. 1. The scheme of the positron annihilation processes according to the 3-statetrapping model. The horizontal lines represent the free state of positron, i.e. the delocalized state of positron in bulk material and its two localized states (defect 1 and defect 2) in two types of defects. $\lambda_{\mathrm{f}}$ is the annihilation rate of the delocalized (free) positron from the bulk, $\lambda_{1}$ and $\lambda_{2}$ are the annihilation rates from two different types of defects, respectively. $\mu_{1} c_{1}$ and $\mu_{2} c_{2}$ are the trapping rates into these defects, which are proportional to the defect concentrations. 
common values for all of the spectra of the series. During the analysis, a source correction $(9.6 \%$ of $105 \mathrm{ps}$ and $3 \%$ of $380 \mathrm{ps}$ ) was made.

The spectra were preliminarily analyzed with the three-state trapping model ${ }^{\dagger}$ $[16,17]$ describing the positron annihilations in the bulk material and two types of defects (Fig. 1). However, it turned out that the number of states in the trapping model could be reduced to two only: for the samples from $\mathrm{DO}_{3}$ region the two states related to the bulk annihilations and annihilations in one type of defects, whereas for the samples from B2 region the states were ascribed to annihilations in two different types of defects. Therefore, the final analysis was made separately for the spectra of samples with 28 at $\% \mathrm{Al}$ and separately for the spectra of samples with higher $\mathrm{Al}$ content. In the first case, the spectra were fitted by the 2-statetrapping model and in the second case by a sum of two exponential components of lifetimes $\tau_{1}$ and $\tau_{2}$.

\section{Results and discussion}

\subsection{Vacancy formation in the $\mathrm{DO}_{3}$ region}

As it was mentioned, the positron lifetime spectra of samples containing 28 at\% $\mathrm{Al}$ (with and without $\mathrm{Cr}$ ) after different heat treatment were analyzed as a series of experimental data by the 2 -state trapping model. The fitted model parameters were $\tau_{\mathrm{f}}=1 / \lambda_{\mathrm{f}}, \tau_{1}=1 / \lambda_{1}$ and $\mu_{1} c_{1}$ (Fig. 1). Since we expected that the heat treatment of samples and the small addition of $\mathrm{Cr}$ did not influence the lifetimes $\tau_{\mathrm{f}}$ and $\tau_{1}$ significantly, we constrained these parameters at common values for all of the spectra in this series. In the result we obtained $\tau_{\mathrm{f}}=142 \pm 7 \mathrm{ps}$ and $\tau_{1}=170 \pm 2 \mathrm{ps}$ (the first row in Table II). According to the literature [37 , vacancies in the $\mathrm{Fe}$ sublattice $\mathrm{V}_{\mathrm{Fe}}$ are the dominant type of defects in $\mathrm{Fe}-\mathrm{Al}$ system (maybe organized in triple defects, i.e. two vacancies and an antiside atom $[5,7])$. This very high concentration of vacancies in the system can be explained by their low formation enthalpy (especially in the $\mathrm{DO}_{3}$ region, e.g. for $\mathrm{Fe}_{69} \mathrm{Al}_{31}$ the vacancy formation enthalpy is $0.73 \mathrm{eV}$ [8]). Broska et al. [9] determined the positron lifetime in $\mathrm{V}_{\mathrm{Fe}}$ as $174 \pm 2 \mathrm{ps}$ for $\mathrm{Fe}_{69} \mathrm{Al}_{31}$. Present value of $\tau_{1}=170 \pm 2 \mathrm{ps}$ is very similar; therefore we indicate $\tau_{1}$ as positron lifetime in $\mathrm{V}_{\mathrm{Fe}}$.

TABLE II

The lifetimes of positron annihilates from the free state $\left(\tau_{\mathrm{f}}\right)$ and two different defect states.

\begin{tabular}{c|c|c|c}
\hline \hline Sample & $\tau_{\mathrm{f}}[\mathrm{ps}]$ & $\tau_{1}[\mathrm{ps}]$ & $\tau_{2}[\mathrm{ps}]$ \\
\hline 28A, CrA $\ldots$ of different heat treatment & $142 \pm 7$ & $170 \pm 2$ & - \\
\hline 38A, 42A, 45A & - & $172 \pm 2$ & $214 \pm 13$
\end{tabular}

\footnotetext{
${ }^{\dagger}$ The 3 -state as well as 2-state trapping models are introduced into the code of the program and the parameters of models are the fitting parameters directly.
} 
During the numerical analysis, on the contrary to the lifetimes (whose respective values had to be common for all of the analyzed spectra), the parameter $\mu_{1} c_{1}$ was entirely free, so it could change from spectrum to spectrum. The resulting values of $\mu_{1} c_{1}$ for different sample compositions and heat treatments are shown in Fig. 2. The comparison of $\mu_{1} c_{1}$ for the samples 28A and CrA shows that the chromium addition caused a decrease in the resistant $\mathrm{V}_{\mathrm{Fe}}$ concentration. This result agrees with literature [3-8, 10-12], where it has been concluded that a small addition of $\mathrm{Cr}$ reduces the vacancy concentration that leads to lowering of the hardness of the material.

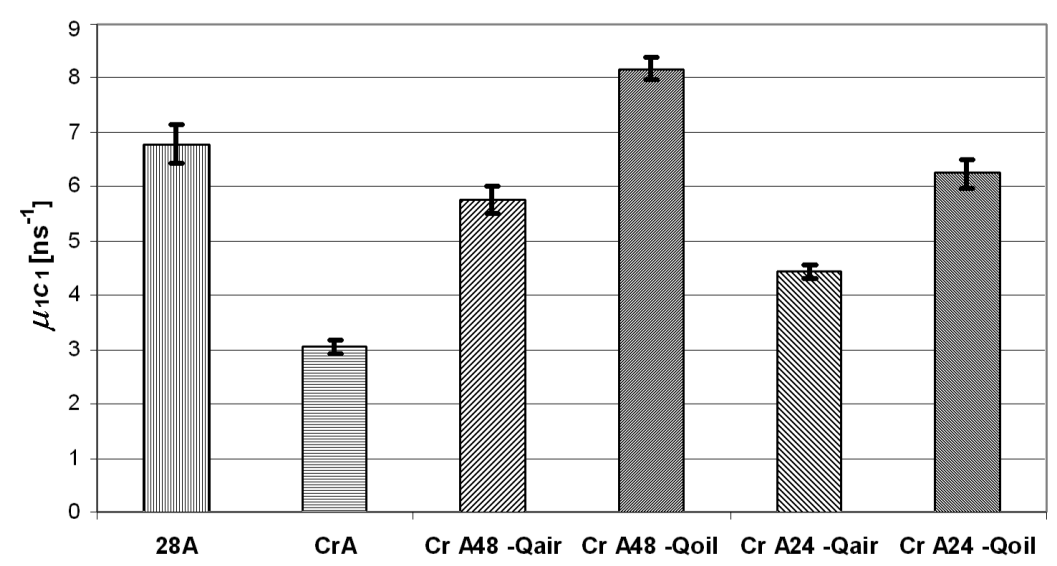

Fig. 2. The positron trapping rate into the resistant vacancies in the Fe sublattice in $\mathrm{Fe}-\mathrm{Al}$ and $\mathrm{Fe}-\mathrm{Al}-\mathrm{Cr}$ after different heat treatment of samples. The symbols of samples used in the figure are explained in Table I.

It is well known that the heat treatment modifies the defect structure of aluminides, therefore we studied influence of the annealing time and quenching medium on the vacancy concentration in Fe28Al5Cr. The study showed (Fig. 2) that according to expectation, the quenching to oil is more effective than quenching to air. The higher $\mathrm{V}_{\mathrm{Fe}}$ concentration in the samples annealed for $48 \mathrm{~h}$ in comparison to the samples annealed for $24 \mathrm{~h}$ (quenched to the same medium), suggests that annealing for $24 \mathrm{~h}$ is not sufficient to reach the thermal equilibrium in the samples.

\subsection{Vacancy formation in the B2 region}

Figure 3 (upper curve) shows the composition dependence of mean positron lifetime $\left(\tau_{\mathrm{m}}\right)$ for the $28 \mathrm{~A}-45 \mathrm{~A}$ samples (see Table I). The mean lifetime increases with Al content. Similar values of $\tau_{\mathrm{m}}$ as well as a similar dependence of $\tau_{\mathrm{m}}$ on Al content were observed by other authors [6]. Haragushi et al. [11] observed $\tau_{\mathrm{m}} \approx 180 \mathrm{ps}$ for Fe41Al slowly cooled from $1000^{\circ} \mathrm{C}$. Studying Fe40Al and Fe $48 \mathrm{Al}$ quenched from $1000^{\circ} \mathrm{C}$, Gialanella et al. [7] found $\tau_{\mathrm{m}} \approx 182 \mathrm{ps}$ and $192 \mathrm{ps}$, 
respectively. Broska [9] et al. determined $\tau_{\mathrm{m}}$ increasing in the range (160-185) ps with the increase in $\mathrm{Al}$ content from 25 to 48 at\%.

The observed increase in $\tau_{\mathrm{m}}$ with growing $\mathrm{Al}$ concentration was explained [36] by a change in the existing defect structure or the formation of a new defect type. Our studies seem to confirm the latter thesis that the observed increase is caused by formation a new type of defects but not by changes in the structure of defects existing yet: the results (Table II) show that only one defect type (characterized by the lifetime $\tau_{1}$ ) is present in the $\mathrm{Fe}-\mathrm{Al}$ samples from $\mathrm{DO}_{3}$ region whereas in the samples from $\mathrm{B} 2$ region, there are two types of defects. First type of defects, of major contribution, is characterized by lifetime $\tau_{1}$, equal (in the statistical error range) to the positron lifetime for $\mathrm{V}_{\mathrm{Fe}}$ in $\mathrm{DO}_{3}$ region, i.e. $172 \pm 2$ ps. Therefore we suggest that these defects are also vacancies in Fe sublattice. We ascribe supposedly, the second type of defects in $\mathrm{DO}_{3}$ region, connected with a lifetime of value $\tau_{2}=214 \pm 13 \mathrm{ps}$, according to the suggestion of Broska et al. [9], to vacancies in the $\mathrm{Al}$ sublattice $\left(\mathrm{V}_{\mathrm{Al}}\right)$.

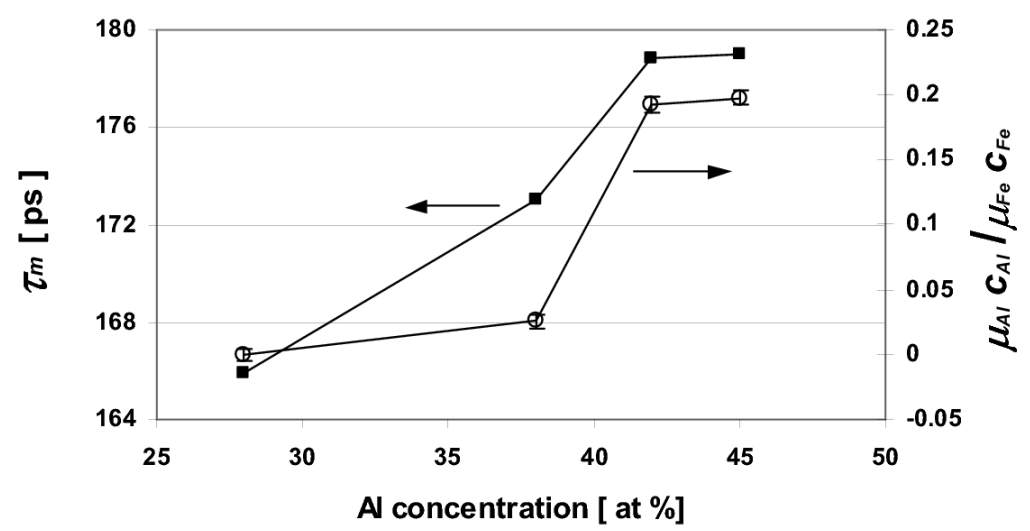

Fig. 3. Mean positron lifetime $\tau_{\mathrm{m}}$ (upper curve) and the ratio of the trapping rates $\mu_{\mathrm{A}} c_{\mathrm{A}} / \mu_{\mathrm{Fe}} c_{\mathrm{Fe}}$ into two different types of defects, i.e. $\mathrm{V}_{\mathrm{Al}}$ and $\mathrm{V}_{\mathrm{Fe}}$ (bottom curve) as a function of $\mathrm{Al}$ content for $\mathrm{Fe}-\mathrm{Al}$ samples slowly cooling after annealing at $1000^{\circ} \mathrm{C}$ for $48 \mathrm{~h}$. The error bars for $\tau_{\mathrm{m}}$ are enclosed inside the graphic symbols.

Figure 3 (bottom curve) represents the ratio $\mu_{\mathrm{Al}} c_{\mathrm{Al}} / \mu_{\mathrm{Fe}} c_{\mathrm{Fe}}$ of the positron trapping rates into $\mathrm{V}_{\mathrm{Al}}$ and $\mathrm{V}_{\mathrm{Fe}}$ as a function of $\mathrm{Al}$ content, which is proportional to the concentration ratio $c_{\mathrm{Al}} / c_{\mathrm{Fe}}$ of these two types of defects. It is seen that the ratio increases very strongly in the range $38-42$ at $\% \mathrm{Al}$ and then is almost constant. This dependence is very similar to dependence of $\tau_{\mathrm{m}}$ on $\mathrm{Al}$ content. Therefore it is reasonable to claim that the increase in $\tau_{\mathrm{m}}$ with $\mathrm{Al}$ content, observed in this work and literature (Fig. 3 in [9]), is caused by elevating value of $c_{\mathrm{Al}} / c_{\mathrm{Fe}}$. 


\section{Conclusions}

In the full investigated range of $\mathrm{Al}$ content in $\mathrm{Fe}-\mathrm{Al}$ system, the same dominant type of defect (more probably - vacancy in the Fe sublattice) is present.

In the $\mathrm{Fe}-\mathrm{Al}$ samples from $\mathrm{DO}_{3}$ region, the vacancy concentration is relatively low so the positron trapping is not saturated, which enables one to observe the influence of a ternary addition and different heat treatment on changes in the defect concentration.

For samples from the range of 38-42 at\% Al, the total concentration of defects is so high that the positrons are exclusively trapped by defects. Above 38 at\% $\mathrm{Al}$, some amount of vacancies in $\mathrm{Al}$ sublattice $\left(\mathrm{V}_{\mathrm{Al}}\right)$ is formed. The concentration ratio of $\mathrm{V}_{\mathrm{Al}}$ to $\mathrm{V}_{\mathrm{Fe}}$ elevates with $\mathrm{Al}$ content and reaches a quite high $(\approx 20 \%)$ and almost saturated value for $\mathrm{Al}$ concentration above 42 at $\%$.

\section{Acknowledgments}

The work was supported by the State Committee of Scientific Research, grant no. PB-581/T/2006.

\section{References}

[1] J.L. Jordan, S.C. Deevi, Intermetallics 11, 507 (2003).

[2] D.G. Morris, M.A. Morris-Mudoz, Intermetallics 7, 1121 (1999).

[3] B. Bergson, M.J. Stott, Solid State Commun. 7, 1023 (1930).

[4] D.C. Conners, R.N. West, Phys. Lett. A 30, 24 (1969).

[5] M. Kogachi, T. Haraguchi, S.M. Kim, Intermetallics 6, 30 (1924)69.

[6] M. Hillert, M. Selleby, J. Alloys Comp. 329, 208 (2001).

[7] S. Gialanella, R.S. Brusa, W. Deng, F. Marino, T. Spataru, G. Principi, J. Alloys Comp. 317-318, 485 (2001).

[8] J. Bogner, W. Steiner, M. Reissner, P. Mohn, P. Blaha, K. Schwarz, R. Krachler, H. Ipser, B. Sepiol, Phys. Rev. B 58, 14922 (1998).

[9] A. Broska, J. Wolff, M. Franz, Th. Hehenkamp, Intermetallics 7, 259 (1999).

[10] X. Ren, K. Otsuka, Philos. Mag. A 80, 467 (1900).

[11] T. Haraguchi, M. Kogachi, S.M. Kim, Intermetallics 7, 981 (1999).

[12] A. Hanc, G. Dercz, J. E. Frackowiak L. Pajak, F. Binczyk, in: Proc. XIX Conf. on Applied Crystallography, Eds. H. Morawiec, D. Stróż, World Scientific, Singapore 2004, p. 312.

[13] A. Hanc, J.E. Frąckowiak, Nukleonika 49, S3, 7 (2004).

[14] J. Kansy, in: Proc. 34th Polish Seminar on Positron Annihilation, Ed. K. Jerie, Turawa 2002, p. 179, in "Help" of the LT-9 computer program.

[15] J. Kansy, Nucl. Instrum. Methods Phys. Res. A 374, 235 (1996).

[16] B. Bergson, M.J. Stott, Solid State Commun. 7, 1023 (1963).

[17] D.C. Conners, R.N. West, Phys. Lett. A 30, 24 (1969). 